\title{
Analysis of the power system impacts and value of wind power
}

\author{
Mel George \\ Bharat Petroleum Corporation Ltd., Corporate R\&D Centre, Greater Noida, INDIA* \\ e-mail: melgeorge@iitb.ac.in, Tel +91-120-2354194, Fax.+91-120-2354172
}

\begin{abstract}
Present electricity grids are predominantly thermal (coal, gas), hydro and nuclear based. Conventional power planning involves hydro-thermal scheduling and merit order dispatch. In the future, modern renewables (wind, solar, biomass) are likely to have a significant share in the power sector. This paper presents a method to analyse the impacts of wind power in the electricity grid. The short term and long period effects of wind power on the grid are elaborated. A duration curve based approach has been developed. Wind energy has been treated as negative loads to obtain a modified load duration curve from which capacity savings in terms of base and peak load generation can be computed. The methodology is illustrated for Tamil Nadu (a state in India). Scenarios for 2021-22 have been constructed to illustrate the methodology proposed. This technique can be useful for power planners for an analysis of renewables in future electricity grids.
\end{abstract}

Keywords: Wind energy, power systems, duration curves, fluctuations

\section{Introduction}

The present share of renewables in most electric grids is marginal. Electricity generation from renewables is assuming increasing importance in the context of rapid and accelerated growth in energy demand and negative environmental externalities due to predominance of fossil fuels in the generation mix. The share of renewables in electricity generation is around $18 \%$, with $15 \%$ of global electricity coming from hydroelectricity and 3.4\% from new renewables (Global Status Report, 2007). In particular, the wind and solar photovoltaic markets show yearly growth rates between $20-30 \%$ in the last few years (Waldau and Ossenbrink, 2004). At the end of 2008, worldwide wind farm capacity was 120,791 megawatts (MW), representing an increase of 28.8 percent during the year, and wind power produced $1.3 \%$ of global electricity consumption. Wind power accounts for approximately $19 \%$ of electricity use in Denmark, 9\% in Spain and Portugal, and 6\% in Germany and the Republic of Ireland (WWEA, 2009). The National Solar Mission is a major initiative of the Government of India and targets the deployment of 20,000 MW of solar power by 2022 (MNRE, 2009).

However, regardless of the type of renewable energy source, there are obstacles to their implementation in the current centralised conventional distribution system. For conventional generation, the methods of analysis for making optimal decisions are well known, but intermittent non-conventional sources pose special problems. Conventional power planning offers techniques for fossil fuel power and hydro power plants. These techniques deal with optimal hydro-thermal scheduling with varying loads, using mathematical approaches. A conventional generation system can be operated to follow the load, which is not possible with nonschedulable renewable power generation technologies. The output of a wind power plant has daily and seasonal variations, depending on the site wind regime and machine/device characteristics. As the share of variable renewable energy increases and becomes significant, issues related to capacity expansion planning and dispatch become important.

This paper illustrates an approach based on the duration curve analysis for generation expansion planning with higher penetration of renewable power. Future scenarios for Tamil Nadu state in India for 2021-22 have been illustrated using this methodology.

\footnotetext{
${ }^{*}$ This work was done by the author while at the Indian Institute of Technology (IIT), Bombay.
} 


\section{Effects of wind energy on the power system}

The power system requirements of wind power depend mainly on the power system configuration, installed wind power capacity and variation of wind power production. Wind resource variation on time scales of seconds to years affect the power system. An analysis of this impact will be based on the geographical area of interest. The impact of wind energy in the grid has been generally represented in literature in terms of the capacity credit. The capacity credit of wind power has been defined as fraction of installed renewable capacity by which conventional capacity can be reduced without a loss in security of supply (Giebel, 2006). It has been shown that calculating the capacity factor of the resource over a relevant time period usually provides a good estimate of capacity credit (Milligan and Parsons, 1997; Milligan and Porter, 2005). Another method is to compute the wind power generation for time periods corresponding to high systems risk hours or approximate the system LOLP (Loss of Load Probability) curve so that high risk hours receive more weight than other hours. Most methods to assess the capacity credit of a wind power plant are based on a related reliability measure called the Loss of Load Expectation (LOLE) (Milligan and Parsons, 1997; Wijk et al., 1992). However, the total amount of energy generated by a specific technology does not by itself indicate the full value of that technology. The contribution is intermittent and its value is dependent on the correspondence with the major part of the demand. For seasonal wind/ solar regimes like India, neither the capacity factor, nor the capacity credit reflects the monthly variation in the renewable energy generation (George and Banerjee, 2009).

Power from renewable sources (predominantly considered here as wind power) introduces more uncertainty in operating a power system: it is variable and partly unpredictable. To meet this challenge, there will be need for more flexibility in the power system. How much extra flexibility is needed depends on the one hand on how much wind power there is and on the other hand on how much flexibility there exists in the power system (IEA, 2007). The impacts of wind power on the system can be categorised as short-term or long-term. The short term effects involve the cost of balancing the system on the operational time scale (from several minutes to several hours) and are primarily due to fluctuations in power output generated from wind. The short term effects include voltage management issues, impacts on production efficiency of hydro and thermal units, positive or negative impacts on transmission or distribution efficiency, primary and secondary reserve control and loss of energy from wind (if wind power exceeds the amount the system can absorb). Other impacts include those on fuel consumed and emissions from the thermal power units.

The long term effects pertain to adequacy of power capacity. The variable power output from renewables will have an impact on power system reliability and efficiency. These impacts may be positive or negative. The reliability of the power system includes the analyses for ensuring sufficient electricity production within the system to meet the load demand or constraints within the transmission and distribution system. System adequacy is associated with static conditions of the system, and studied either by a simple generation load model or by an extended bulk transmission system model consisting of generation, transmission, distribution and load. The criteria that are used for the adequacy evaluation include the loss of load expectation (LOLE) and the loss of load probability (LOLP), for instance (Holttinen, 2008).

Many studies with respect to the effects of grid integration of wind power in European countries (IEA, 2007; Holttinen, 2008; Holttinen et al, 2007; Gross et al, 2006; Akhmatov and Knudsen, 2007) have reported that the major challenges include impacts on power system operating costs, power quality, imbalances and transmission and scheduling planning. The reported results indicate that wind power impacts are small at low penetrations (about 5\% or less) and the effects remain moderate with penetrations approaching $20 \%$. Georgilakis (2008) states that as penetration of renewables increases, they become progressively less valuable for saving thermal capacity. However, no values have been cited. Also, there still are no concrete results with respect to much higher penetrations of wind power. A consolidated research project between major European countries along with the IEA is still reviewing these aspects (IEA, 2007). With respect to the India, the results from a simulation by Hossain (1993) for Tamil Nadu indicate reliable penetration levels of $25-30 \%$ of the conventional power system.

Very little is known about the realizable levels of penetration for countries like India. More importantly, unlike the developed countries, the capacity expansion and evolution of generation system is continuing in India. The opportunity to plan and control the evolution of the system with a reasonable component of renewables is still open. Despite the large potential of renewables and the need for such studies, no attempts have so far been made to address the issues of integration of significant amounts of renewable energy within the Indian power system. Conventional power planning offers techniques for fossil fuel power and hydro power plants. The output of a wind power plant has daily and seasonal variations, depending on the site wind regime and machine characteristics. As the share of wind energy increases and becomes significant, issues related to capacity expansion planning and dispatch become important.

\section{Wind energy impact assessment framework}

\subsection{Proposed methodology}

This paper outlines a method which can be used to quantify the savings achieved under higher penetration of renewables in the grid. Here, we propose a methodology based on the annual Load Duration Curve (LDC) to assess impacts of wind power on the power system.

The model is developed in a sequential manner, as described below: 
1. Major sites for wind energy generation are considered.

2. Long period (over 10 year) average hourly wind speed data for each representative site is obtained.

3. The wind speeds are then extrapolated to the hub height using the Power Law Index (PLI) for each site. The equation used here is:

$$
\frac{v_{2}}{v_{1}}=\left(\frac{z_{2}}{z_{1}}\right)^{\alpha}
$$

Where $\mathrm{v}_{2}$ and $\mathrm{v}_{1}$ are wind velocities at heights $\mathrm{z}_{2}$ and $\mathrm{z}_{1}$ respectively. $\alpha$ is PLI for the given site.

4. Using the existing installed capacity values and the equipment characteristics, the hourly output from a generator is computed

5. The output powers for each site are summed up and weighted based on installed capacity at each site to obtain the total hourly wind energy generation for the state.

6. The hourly generation data for wind is compared with the actual hourly load demand. The annual load duration curve with and without wind energy is drawn and savings obtained are calculated. The flowchart for the micro model is shown in Figure 1.

7. The energy replaced is estimated from the area between the two load duration curves. The capacity savings are calculated considering the load savings from wind power at 6000 hours (considered as base load savings) and at 15\% of peak load hours (considered as peak load savings). The exercise is repeated for different penetrations of renewables.

8. The method is extended to future scenario modelling by including a capacity expansion model, which is calculated from the Gross Domestic Product (GDP) growth rate and elasticity. New load duration curves are drawn by extrapolating the existing LDC with the energy growth rate.

Different hypothetical renewable energy capacities may be used for the simulations and savings for each can be obtained.

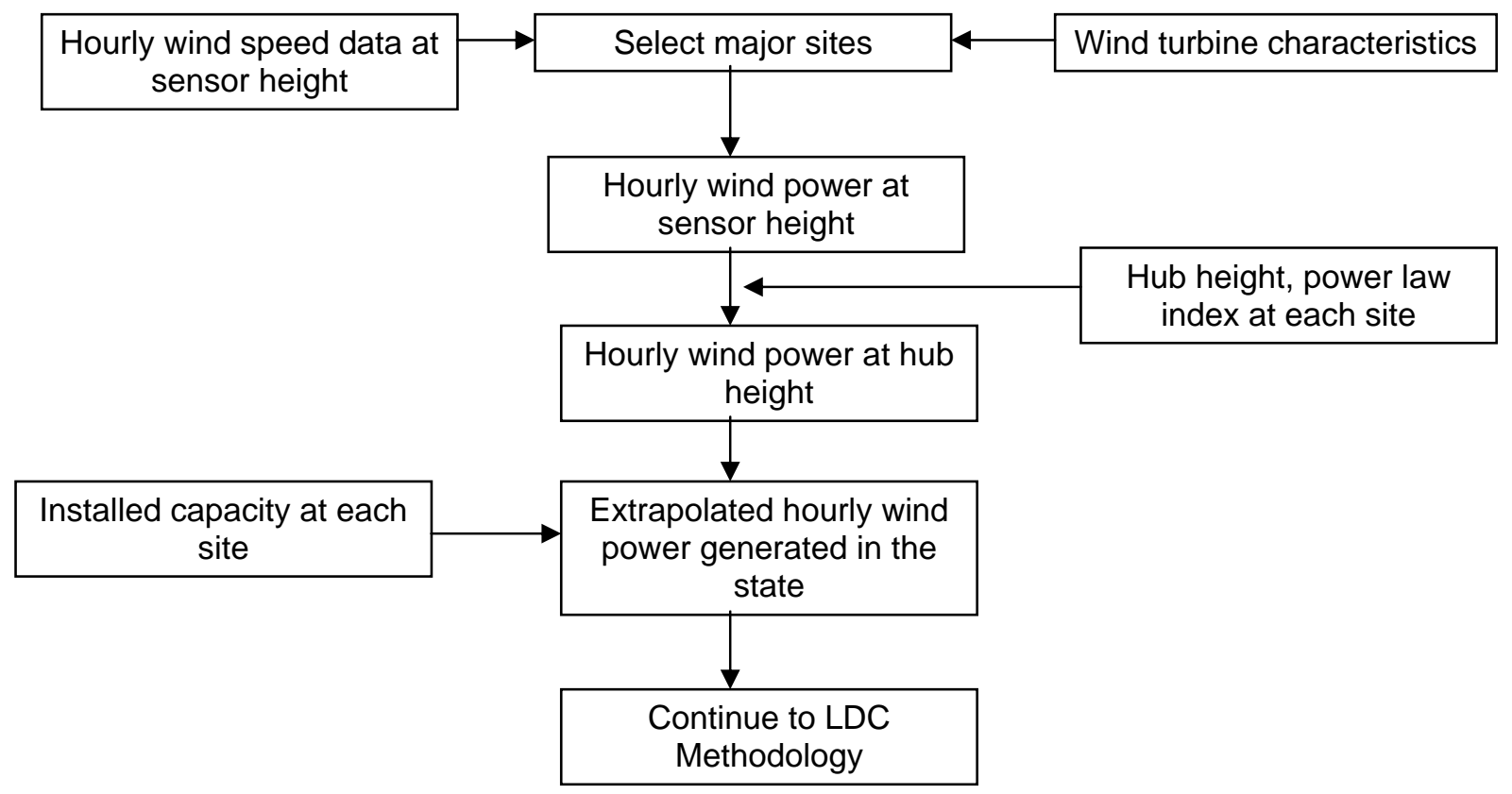

Figure 1: Micro model for wind power output

\subsection{Illustration}

A Load Duration Curve (LDC) is used to illustrate the relationship between generation capacity requirements and capacity utilisation. It is similar to a load curve but the demand data is ordered in descending order of magnitude, rather than chronologically. The LDC shows the capacity utilization requirements for each increment of load. The height of each slice is a measure of capacity, and the width of each slice is a measure of the utilization rate or capacity factor. The product of the two is a measure of electrical energy (e.g. kWh). Load duration curves are constructed by dividing the chronological loads into different time periods. The smaller the steps, more is the chronological information retained.

The effect of adding intermittent renewable resources into the system can be modelled as a negative demand (Wijk et al, 1992; Castro et al, 1996; Fsadni and Mallia, 2006) which accounts for the inherent fluctuations of the produced power. The LDC methodology identifies the same trends as hour-by-hour simulations. 
Here, the power system is characterised as a black box to which different power stations are connected in order to share the required energy supply. This system is characterised by the load duration curve which accounts for the needs of electricity consumers. The consequences of adding non-schedulable generation depends on how it changes the effective load duration curve. The main impact is a saving in energy and capacity requirements from existing generation facilities. The energy replaced is readily estimated by the difference between the two load duration curves.

To encapsulate the load duration characteristics of the demand, the load was segmented into separate load bins (each of 100 MW, in this work) and an algorithm was developed to record the number of hours during the year when the load was within the range of the bin. The energy to be served in each bin is found by multiplying the number of hours in the bin by the median value of the bin. The programming was done using MATLAB 7.1. Considering the base load to last for 6000 hours and average peak load to be the average of $15 \%$ of the highest load hours, the base and average peak capacity values were obtained for different penetrations of wind.

The use of the method is shown using two general load duration curves in Figure 2.

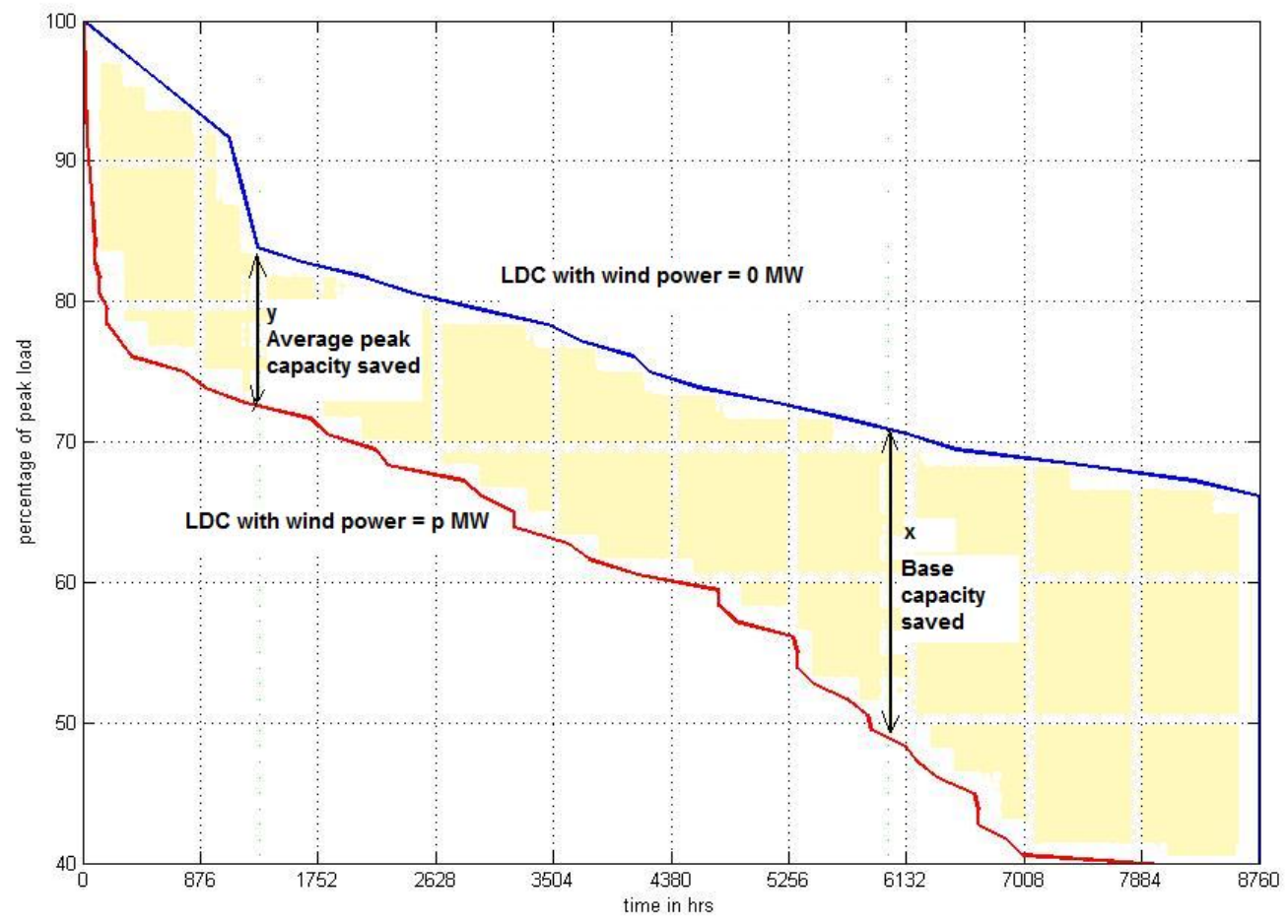

Figure 2: Generalised illustration of LDC methodology

The figure shows two general load duration curves, without and with wind power (wind power considered as negative load on the system). The shaded region shows total energy supplied by wind power. ' $x$ ' denotes the base capacity saved due to wind power. It is calculated from the difference of the two LDCs at the $6000 \mathrm{hr}$. point. ' $\mathrm{y}$ ' is the average peak capacity saved and is computed by averaging the difference between the two LDCs in the region up to $15 \%$ of the peak load hours (about $1300 \mathrm{hrs}$.).

\subsection{Projections for the future}

The LDC methodology proposed above can also be used to plan capacity expansions in future. Different scenarios can be considered and each option's technical potential and inputs evaluated.

The load duration profile for the state system in future is developed using projections for the Gross Domestic Product (GDP) growth rate and elasticity. Here, it is assumed that the load shape will remain the same, but the method can incorporate a change in the future load profile. In general, the methodology for scenario development is shown in Figure 3. 


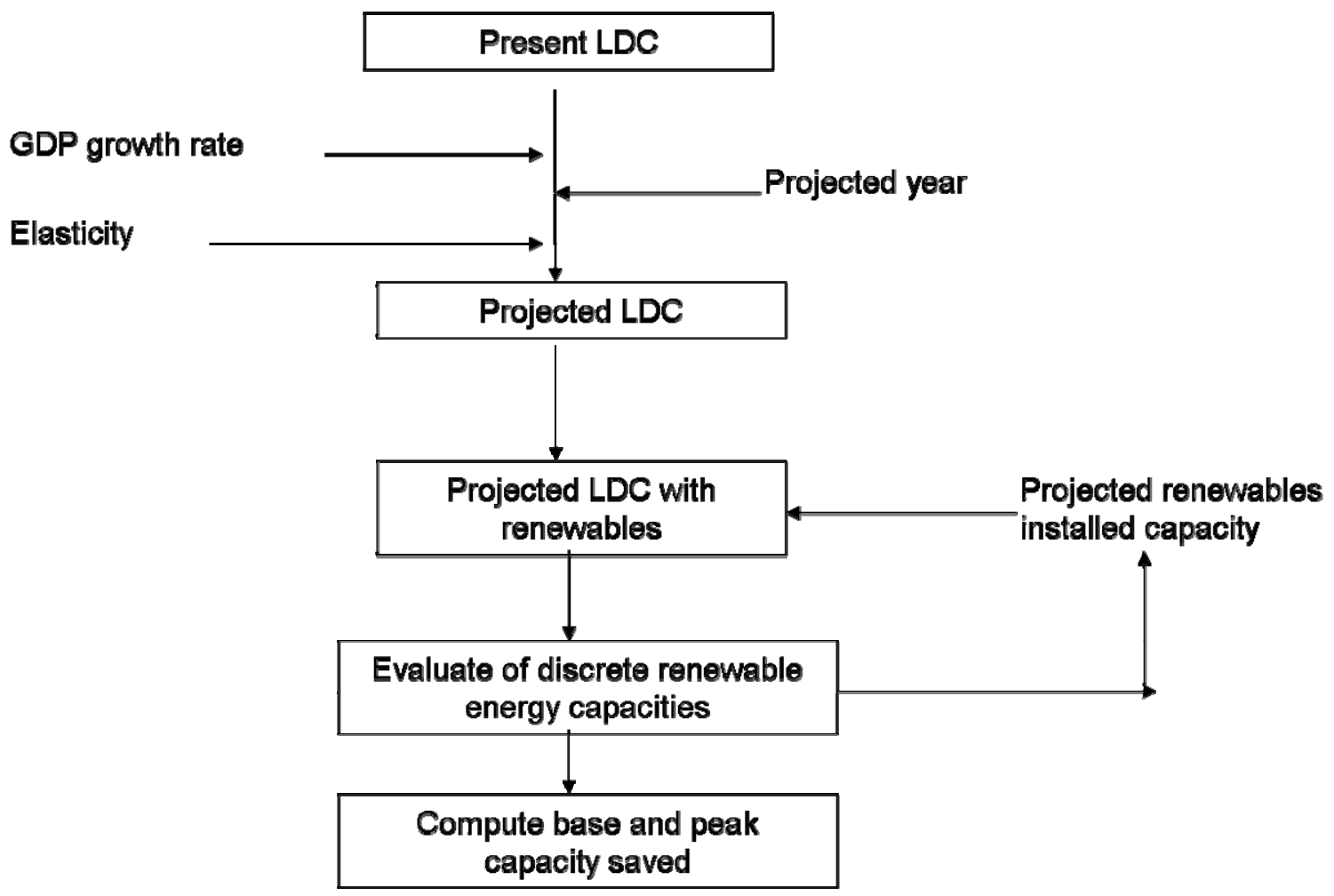

Figure 3: Extension of LDC methodology for future scenario assessments

\section{Case Study: Wind Power in Tamil Nadu}

Tamil Nadu, lying between $8^{\circ} 5^{\prime} \mathrm{N}$ to $13^{\circ} 35^{\prime} \mathrm{N}$ and $76^{\circ} 15^{\prime} \mathrm{E}$ to $80^{\circ} 20^{\prime} \mathrm{E}$, is one of the 28 states in India. It has a size (130058 sq. km.), almost equal to Greece and a population of about 66.4 million in 2008 (GoTN, 2009; Census of India, 2009). The location of Tamil Nadu in India is shown in Figure 4, along with the major wind power sites.

The power situation in the state has been summarised in Table 1. It can be seen that wind power constitutes about $27 \%$ of the installed capacity in the state and about $10 \%$ of the generation.

Table 1: Break-up of installed capacity in Tamil Nadu state (TNEB, 2009)

Source

\begin{tabular}{cccc}
\hline Source & $\begin{array}{c}\text { Installed capacity } \\
\text { (MW) }\end{array}$ & $\begin{array}{c}\text { Annual Energy } \\
\text { generated } \\
\text { (MU) }\end{array}$ & $\begin{array}{c}\text { Annual average } \\
\text { capacity factor } \\
\text { (\%) }\end{array}$ \\
\hline Coal & 2970 & 21230 & 81.6 \\
\hline Gas & 424 & 1945 & 52.4 \\
\hline Hydro & 2187 & 6290 & 32.8 \\
\hline Firm central share & 2825 & 17785 & 71.9 \\
\hline Wind (state + private) & 3875 & 5270 & 18.6 \\
\hline $\begin{array}{c}\text { Other renewables (solar PV, biomass } \\
\text { and Bagasse based cogeneration) }\end{array}$ & 556 & 1220 & 25.1 \\
\hline $\begin{array}{c}\text { Independent power projects (coal, } \\
\text { lignite, diesel or gas based) }\end{array}$ & 1180 & 6360 & 61.5 \\
\hline Assistance from other regional grids & 519 & 2280 & 50.1 \\
\hline Total & $\mathbf{1 4 5 3 6}$ & $\mathbf{6 3 3 7 0}$ & $\mathbf{4 9 . 8}$ \\
\hline
\end{tabular}

${ }^{\text {a }}$ Indicates the allotted generation capacity for the state electricity utility from the power plants operated by Central Government owned generation companies

For Tamil Nadu, hourly wind power generation profiles were not available. These were modelled considering the major wind sites and using hourly average wind speed data. The hourly wind power generation curves were developed using the wind turbine characteristics and ten year average wind velocities from four sites in the state (Muppandal, Kethanur, Ayikudy and Kayattar). Figure 4 shows the map of Tamil Nadu with the major wind farmable sites. The installed wind power capacity details and 
potentials at the four chosen sites are given in Table 2. The load curves for the state were obtained from the Southern Regional Power Committee (SRPC, 2009) while wind speed data was taken from Mani (1992).

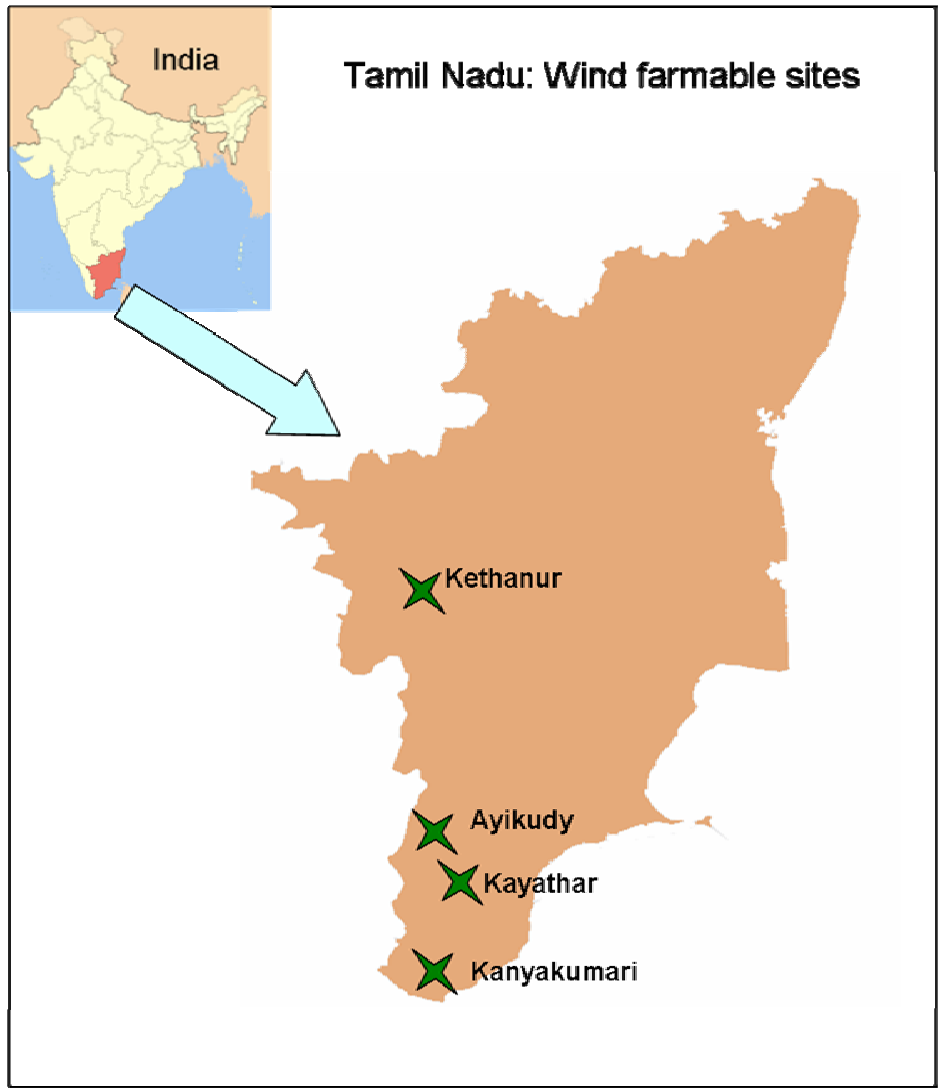

Figure 4: Map of Tamil Nadu, showing location in India and wind farmable sites considered in the simulation

Table 2: Major wind power sites in Tamil Nadu (TEDA, 2009)

\begin{tabular}{|c|c|c|c|}
\hline Site & Location & Estimated potential (MW) & $\begin{array}{c}\text { Present installed capacity } \\
\text { (MW) }\end{array}$ \\
\hline 1 & Kethanur & 1650 & 1552 \\
\hline 2 & Ayikudy & 650 & 381 \\
\hline 3 & Kayathar & 650 & 407 \\
\hline 4 & Muppandal & 2100 & 1508 \\
\hline
\end{tabular}

\subsection{Production patterns of wind power}

The wind speed varies on all time scales, and this has different effects on the power system. Wind gusts cause variations in the range of seconds or minutes. The changing weather patterns can be seen from the hourly time series of wind power production. This time scale also illustrates the diurnal cycle. Seasonal cycles and annual variations, however, are important for long-term adequacy studies. For system planning, it is important to look at extreme variations of large-scale wind power production, together with the probability of such variations.

The daily variation of wind power is shown in Figure 5. It is seen that wind power varies from $500 \mathrm{MW}$ to $2000 \mathrm{MW}$ over a few hours during the day. There is significant variation in the time of occurrence of the peaks and troughs in wind power in different months. Also, there is a wide variation in the monthly energy generated from wind over the year (simulated results shown in Figure 6), with the maximum occurring during June to September (800-1100 MU), and the minimum during March-April and November (100-150 MU), while the average is $500 \mathrm{MU}$. The seasonal wind regime, mainly due to the monsoon, is quite different from the European wind regimes. Few sites have a smaller peak period during December to January due the retreating North-east monsoon winds over the state. 

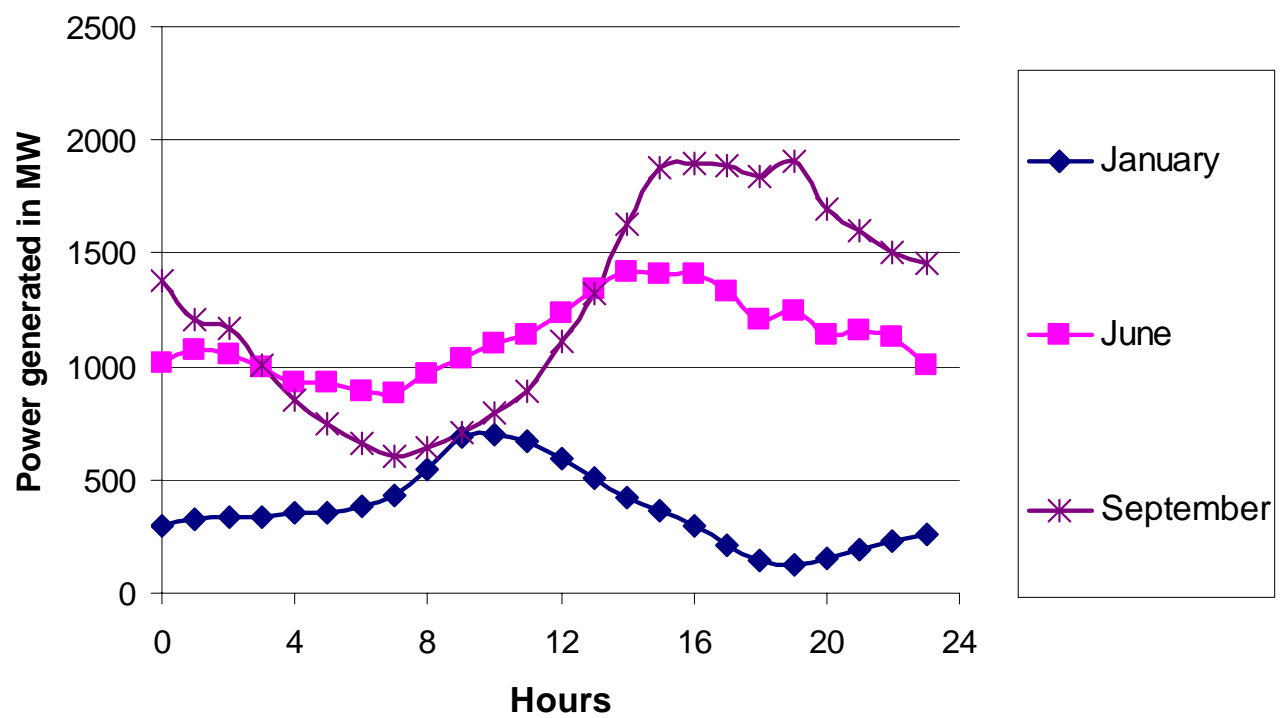

Figure 5: Variation of hourly average wind power in Tamil Nadu for different months

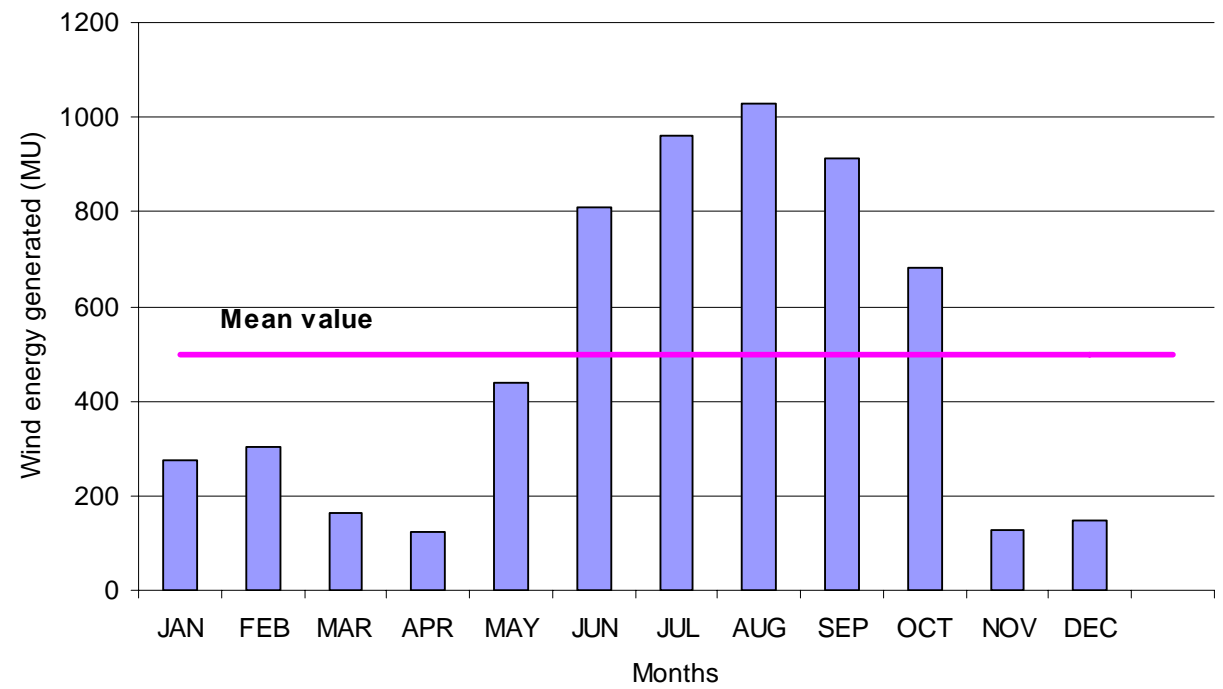

Figure 6: Monthly variation of wind energy generated in Tamil Nadu

\subsection{Duration curves of variations in wind power}

Figure 7 shows a duration curve for wind power generated in Tamil Nadu. It illustrates that maximum production levels are far less than the installed nominal capacity, as the wind does not have the same strength at all sites simultaneously. Also, out of multiple wind turbines, many will not be technically available at each moment. It can be seen that the production is about $10-15 \%$ of the installed capacity for half the year. The wind power generated is about $50-60 \%$ of the installed capacity for a much smaller duration of time. The wind power output rarely reaches $60 \%$ or below $5 \%$ of the installed capacity. The production range is also indicative of the fact that large-scale, geographic dispersion of the wind turbines causes a flattening of the duration curve.

Figure 8 shows the variation of wind power produced in Tamil Nadu between consecutive hours. Although most variations have been smoothed out and are in the $+/-10 \%$ range, frequent variations of $25-40 \%$ are also observed. It is found that that the mean variation is about $11.32 \%$ between hours with a standard deviation of $8.8 \%$. The most extreme ramp rates observed were about $44 \%$ / hour. 


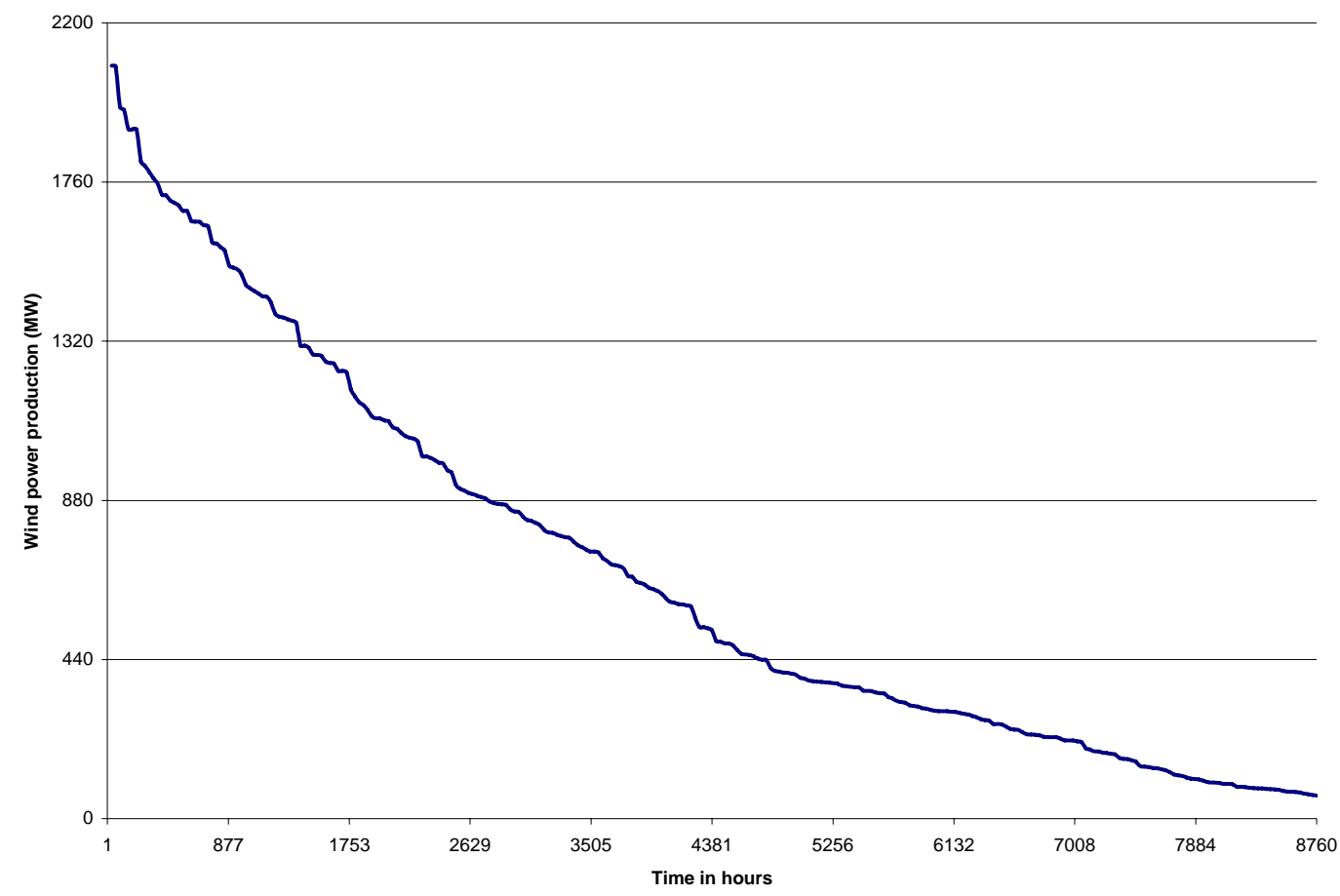

Figure 7: Duration curve for wind power production in Tamil Nadu

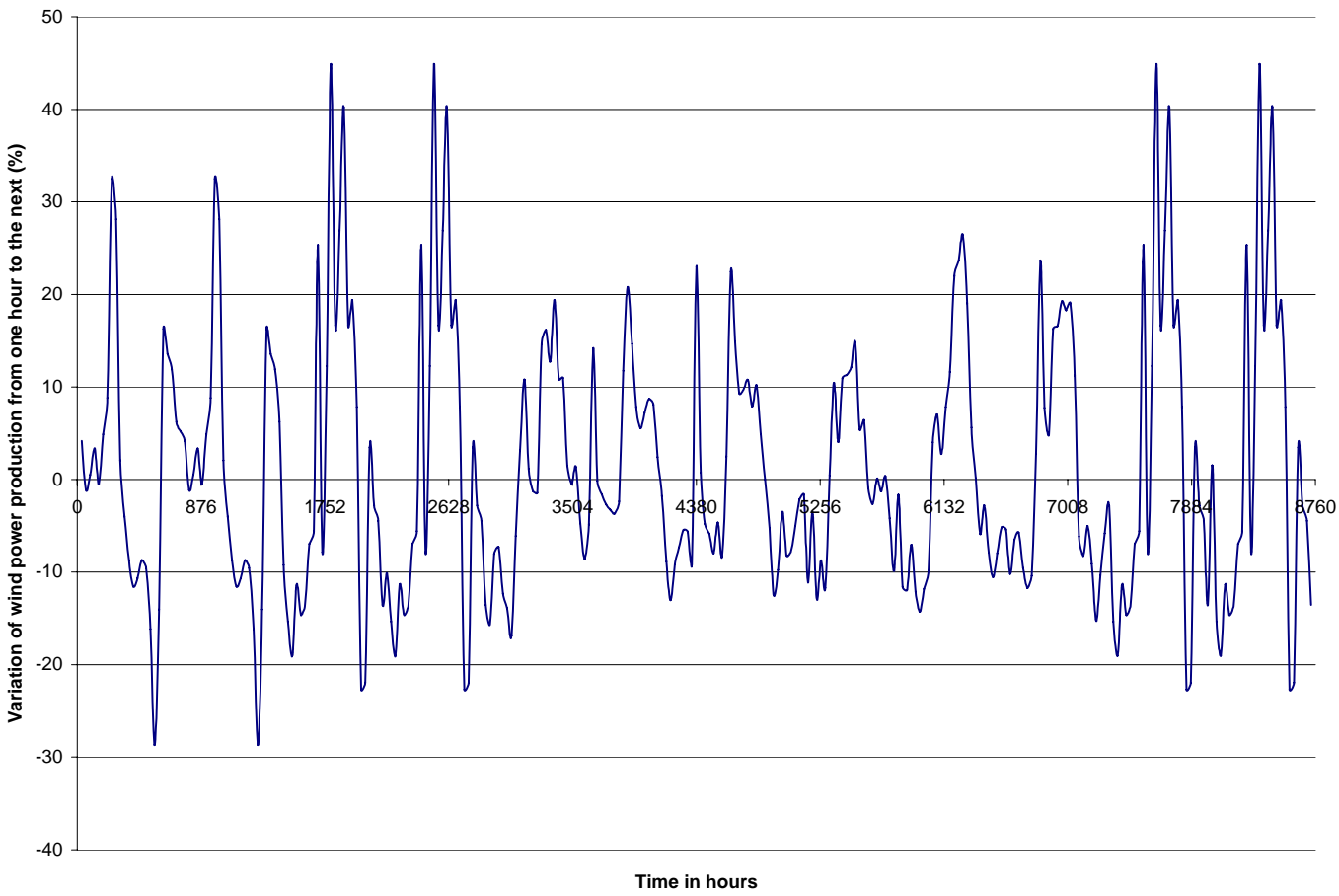

Figure 8: Variation of wind power production from one hour to the next

Revising the results for the fluctuation time series in terms of the installed capacity of wind power, we find that the inter-hour variations are quite small, generally in the range of $+/-3 \%$ of the installed capacity. The mean fluctuation in wind power production between hours is $1.6 \%$ and the standard deviation is found to be $1.41 \%$ of the installed capacity. Ramp rate of up to $9.4 \%$ of the installed capacity per hour have been observed. 


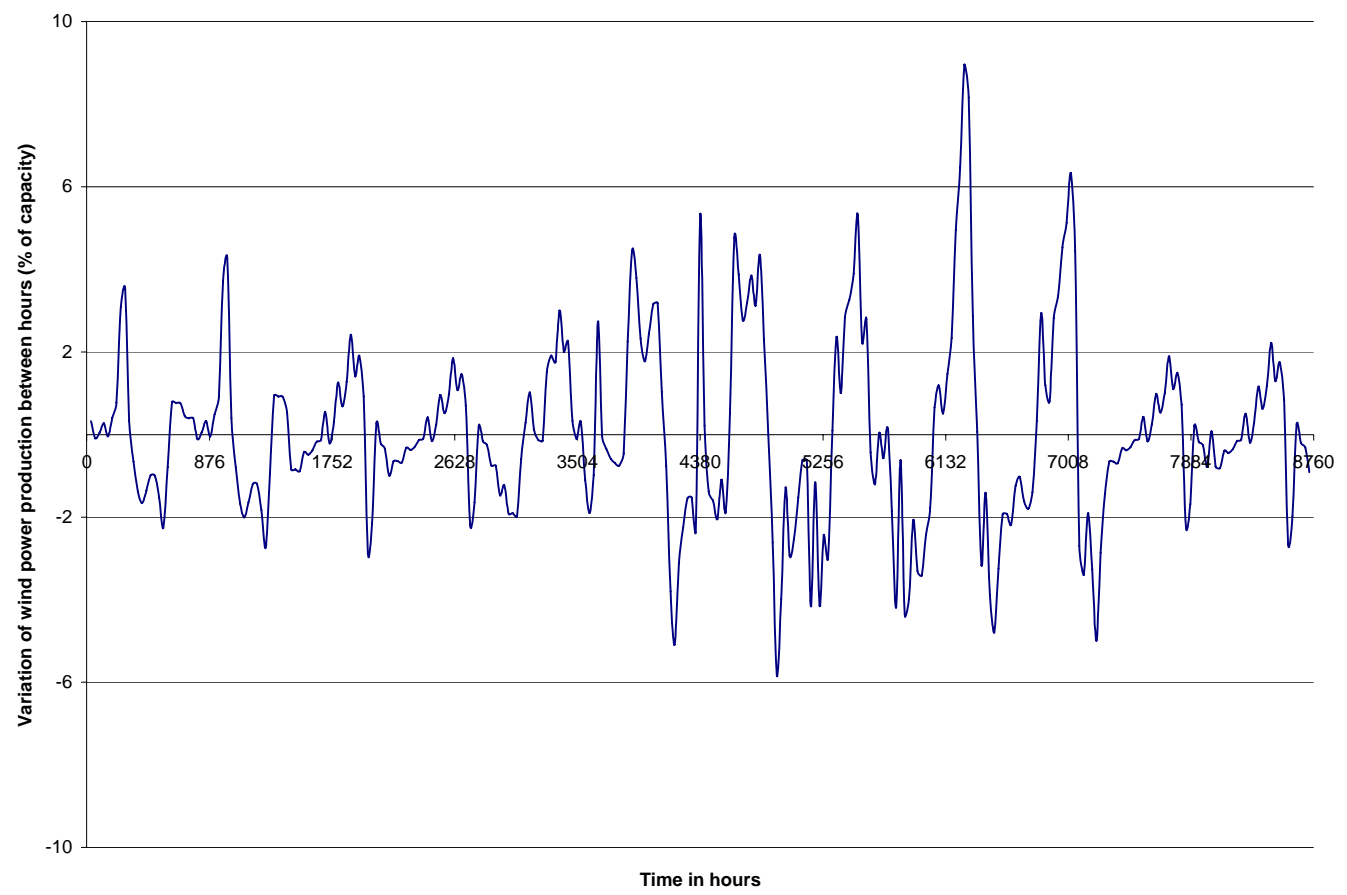

Figure 9: Inter-hour variation of wind power production in Tamil Nadu relative to installed capacity

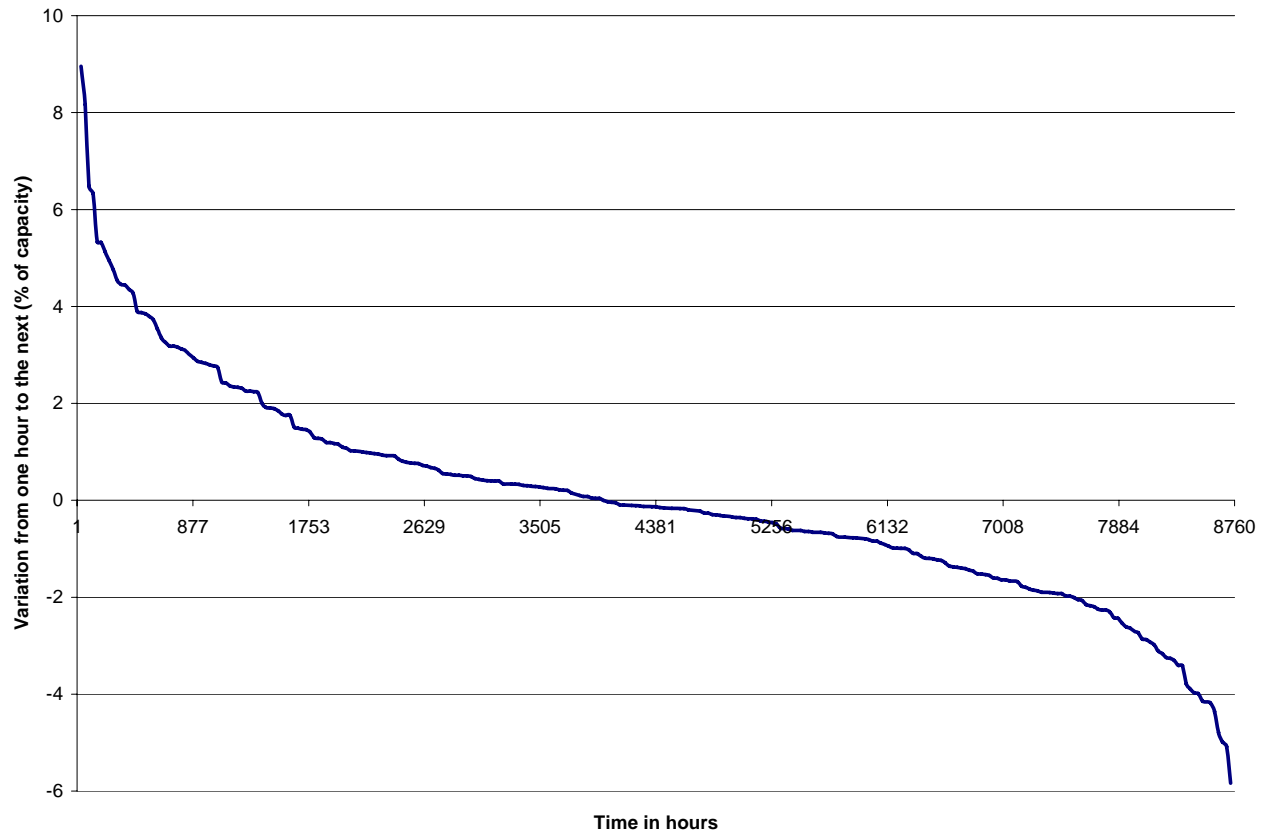

Figure 10: Duration curve of wind power variation between hours, as a percentage of installed capacity

The duration curve of inter-hour wind power fluctuations (Figure 10) shows the largest hourly variation is about $9 \%$ of the installed capacity of wind power in Tamil Nadu. Most of the variations have been smoothed out through geographic dispersion. The inertia of the large rotating blades of a variable-speed wind turbine smoothes out very fast gusts. Second-to-second variations will be absorbed in the varying speed of the rotor of a variable-speed wind turbine. The results compare favorably with the extreme ramp rates that were recorded for a $103 \mathrm{MW}$ wind farm: 4-7\% of capacity in a second, $10-14 \%$ of capacity in a minute and 50 $60 \%$ of capacity in an hour (Parsons et al., 2001). However, system operation is frequently concerned with an area that is much larger than the area in this example. For a larger area, with geographically dispersed wind farms, the second and minute variations will not be significant, and the hourly variations will be considerably less than those observed in this case. 


\subsection{Capacity saving impacts of wind power}

Different wind profiles ranging from $0 \mathrm{MW}$ installed capacity to $100 \%$ of the peak demand ( $9000 \mathrm{MW}$ ) were used and the effect on the annual load duration curve was studied. The impacts of some of these wind profiles on the net load duration curve are shown in Figure 11.

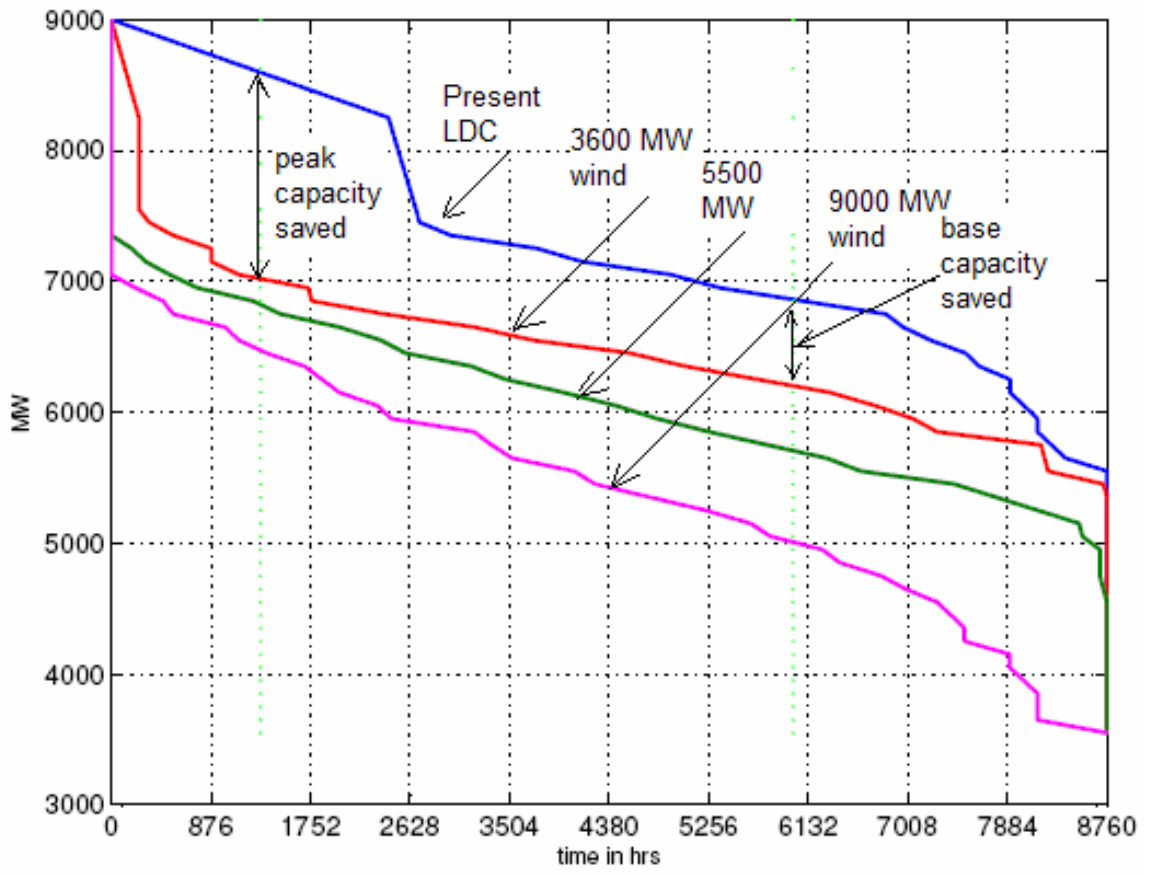

Figure 11: Annual load duration curves for Tamil Nadu under different wind power scenarios

\subsection{Future projections and scenarios}

The load duration profile for the state system in 2021, (when the installed capacity of wind power is expected to reach the estimated potential for the state) was developed using historical data and the projections of the $17^{\text {th }}$ Electric Power Survey (CEA, 2007 ) and has been shown in Figure 12. The report projects a growth rate of $9 \%$ p.a. in GDP and an elasticity of 0.8 , giving an annual average load growth of $7.2 \%$. Here, it is assumed that the load shape will remain the same, but the method can still incorporate a change in the future load profile. Many wind experts (Winrock, 2009; IWEA, 2009) believe that the potential has been underestimated and the actual potential is double the estimated value. Hence, we a scenario with 11,000 MW of wind has also been shown.

The average additional peak demand to be supplied then would be about 3,600 MW and additional peak energy to be supplied is 7,877 MU in the absence of wind power (curve A). Also, an additional 11,300 MW would be required to be added to the base load capacity by 2021 . However, in the presence of $5,500 \mathrm{MW}$ of wind power, the base load capacity addition required would be about 10,200 MW and additional peaking energy to be supplied reduces to $4670 \mathrm{MU}$. Thus, wind power of 5,500 MW in 2021 can lead to savings of about 1,100 MW of base power capacity and about 3,207 MU of peak energy requirement or 2,400 MW in the average peak. Such analysis can be extended to higher wind power penetrations using this method. 


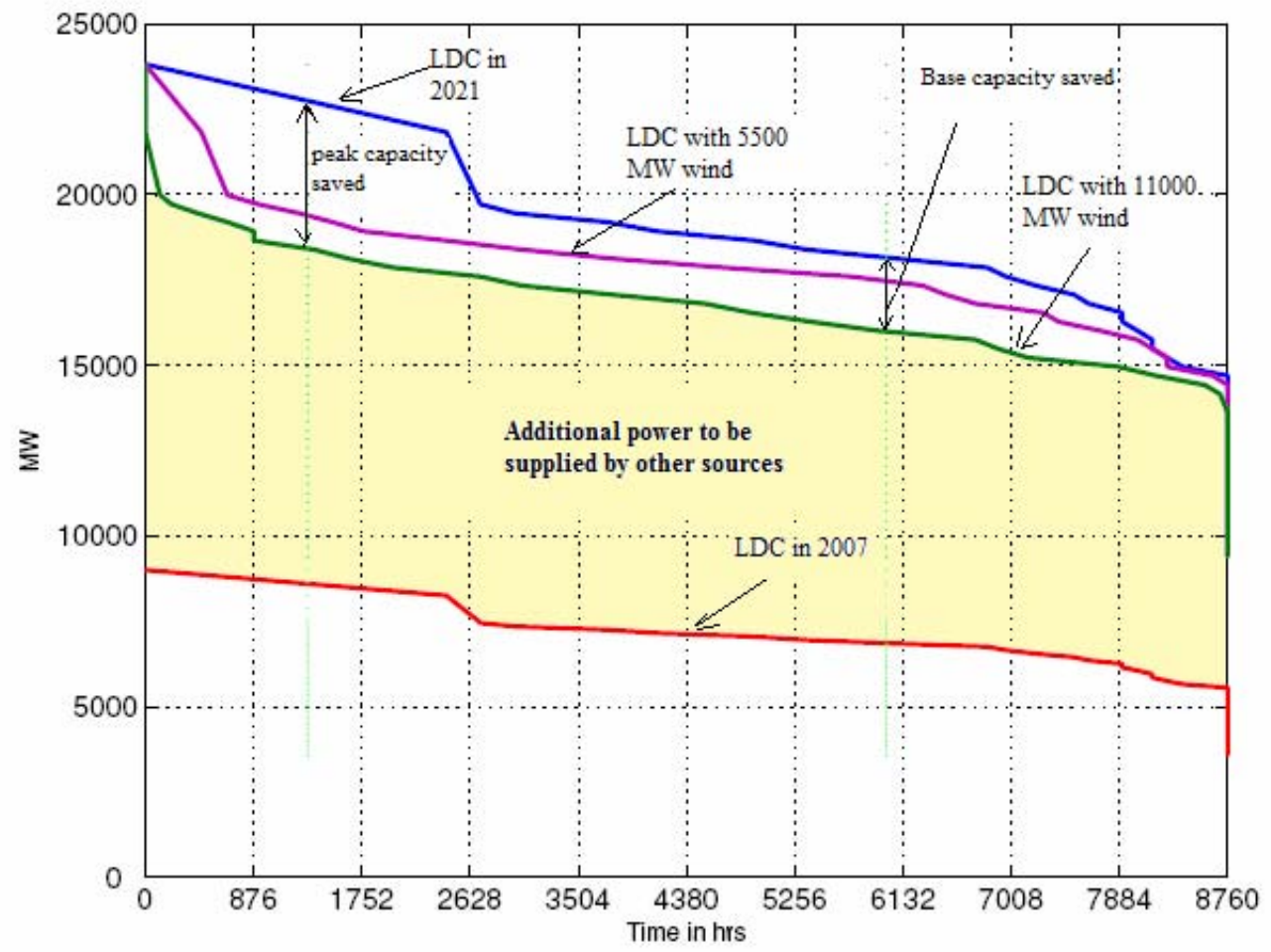

Figure 12: Effect of wind power on load duration curve for Tamil Nadu in 2021-22

\section{Conclusions}

Renewables are gradually entering the mainstream of power generation. With their increasing penetration in the grid, the impacts on the power system need to be explored. The conventional power techniques focus mainly on hydro-thermal coordination. Largescale wind power still lies in the future for many countries. There are long-term trends that can influence the impact of wind power on the system. If there are large amounts of intermittent energy sources in the system, new capacity with lower investment costs (and higher fuel costs) will be favoured. The trend of increasing distributed generation from flexible gas turbines is beneficial for the integration of wind power, as is increasing load management. Wind power will have an impact on power system reserves as well as on losses in generation and transmission or distribution. It will also contribute to a reduction in fuel usage and emissions. Regarding the power system, the drawbacks of wind power are that wind power production is variable, difficult to predict and cannot be taken as given. However, integration of variable sources is much less complicated if they are connected to large power systems, which can take advantage of the natural diversity of variable sources. A large geographical spreading of wind power will reduce variability, increase predictability and decrease occasions of near-zero or peak output. The power system has flexible mechanisms to follow the varying load that cannot always be accurately predicted. As no production unit is $100 \%$ reliable, part of the production can come from variable sources, with a similar risk level for the power system. Power system size, generation capacity mix (inherent flexibility) and load variations have an effect on how intermittent production is assimilated into the system. If the proportion of intermittent power production is small, and if wind power production is well dispersed over a large area and correlates with the load then wind power is easier to integrate into the system.

In this paper, a simple load duration curve methodology with detailed micro-level modelling has been proposed to study the impacts of renewable energy systems in electric utility systems. This methodology has been applied to Tamil Nadu state in India. The savings potential has been calculated in terms of base and peak capacity replaced. Future hybrid scenarios using wind power for 2021-22 have been developed using the methodology. Large-scale wind power still lies in the future for many countries, and there are long term trends that can influence what impact wind power has on the system, such as the use of electricity for vehicles. At high penetration levels, an optimal system may require changes in the conventional capacity mix. The analysis using the proposed method will be useful for power planners to assess the future impacts of increasing renewable energy capacity in different grids and design appropriate strategies for capacity expansion planning. 


\section{Acknowledgements}

The author gratefully acknowledges the guidance and support of Prof. Rangan Banerjee, Dept. of Energy Science and Engineering, Indian Institute of Technology (IIT) Bombay, Mumbai, India. The assistance of Mr. M V Manoj Kumar is also gratefully recognized.

\section{References}

Akhmatov V., Knudsen H., 2007. Large Penetration of Wind and Dispersed Generation into the Danish power Grid, Electric Power System Research, 77, pp. 1228-1238.

Castro, M. A., Carpio, J., Peire, J., Rodriguez, J.A., 1996. Renewable Energy Integration Assessment through a Dedicated Computer Program, Solar Energy, 57 (6), 471 - 484

CEA, 2007. Report on the $17^{\text {th }}$ Electric Power Survey of India, Central Electricity Authority, New Delhi, May 2007.

Census of India, 2009. Projected population, http://www.censusindia.gov.in

Fsadni, M, Mallia, E A, 2006. The Integration of Wind Power Generation with Electricity Demand in the Context of a Small Grid, Renewable Energy, 31, pp. $811-819$

GoTN, 2009. Government of Tamil Nadu, Statistical Handbook, http://www.tn.gov.in/deptst/index.htm

George M, Banerjee R, 2009. Analysis of Impacts of Wind Integration in the Tamil Nadu Grid, Energy Policy; 37 (9), 3693-3700, 2009

Georgilakis P., 2008. Technical Challenges Associated with the Integration of Wind Power into Power Systems, Renewable and Sustainable Energy Reviews, 12, pp. 852-863.

Giebel G, 2006. Wind Power has a Capacity Credit: A Catalogue of 50+ Supporting Studies, WindEng EJournal, windeng.net

Global Status Report, 2007. http://www.ren21.net/pdf/RE2007_Global_Status_Report.pdf

Gross R., Heptonstall P., Anderson D., 2006. The Costs and Impacts of Intermittency, The United Kingdom Energy Research Centre, London, March 2006.

Holttinen H., 2008. Estimating the Impacts of Wind Power on Power Systems - Summary of the IEA Wind Collaboration, Environmental Research Letters, 3, pp. 1-6, 2008.

Holttinen H., Meibom P., Tusslin C., Hoffman L., 2007. State of the Art of Design and Operation of Power Systems with Large Amounts of Wind Power, European Wind Energy Conference, Milan, Italy, May 2007.

Hossain J., 1993. Grid Integration of Renewables in Developing Countries: A Case Study of High Wind Penetration in the Tamil Nadu Electricity Utility, Energy Policy, 8, pp. 868-874.

IEA, 2007. Design and Operation of Power Systems with Large Amounts of Wind Power: State of the Art Report, International Energy Agency, Helsinki, Finland, October 2007.

IWEA, 2009. Indian Wind Energy Association, http://www.inwea.org

Mani A., 1992. Wind Energy Resource Survey in India, vol. II, Allied Publishers, New Delhi.

Milligan M, Parsons B, 1997. A Comparison and Case Study of Capacity Credit Algorithms for Intermittent Generators, Technical Report, National Renewable Energy Laboratory, Colorado, USA.

Milligan M, Porter K, 2005. Determining the Capacity Value of Wind: A Survey of Methods and Implementation, WINDPOWER 2005, Denver, Colorado, USA.

MNRE, 2009. Ministry of New and Renewable Energy, Notes, http://mnes.nic.in/

Parsons, B., Wan, Y., Kirby, B., 2001. Wind Farm Power Fluctuations, Ancillary Services, and System Operating Impact Analysis Activities in the United States, Proceedings of European Wind Energy Conference, 2nd-6th July, 2001, Copenhagen, WIPMunich, Germany, pp. 1146-1149; also available as NREL Report CP-500-30547, available at http://www.nrel.gov/publications/.

SRPC, 2009. Southern Regional Power Committee, Annual and Monthly Reports, Ministry of Power, Govt. of India, http://www.srpc.kar.nic.in/reports.htm

TEDA, 2009. Tamil Nadu Energy Development Agency, http://www.teda.gov.in/page/Wind.htm

TNEB, 2009. Tamil Nadu Electricity Board, http://www.tneb.in/

Waldau A, Ossenbrink H, 2004. Progress of Electricity from Biomass, Wind and Photovoltaics in the European Union, Renewable and Sustainable Energy Reviews 2004; 8 (2): 157-182.

Wijk van A., Halberg N., Turkenburg W., 1992. Capacity Credit of Wind Power in the Netherlands, Electric Power System Research, 23, 189-200

Winrock, 2009. Winrock International, www.winrockindia.org/media desk wininter_1.

WWEA, 2009. World Wind Energy Association, Wind turbines generate more than $1 \%$ of the global electricity, http://www.wwindea.org/home/images/stories/pr_statistics2007_210208_red.pdf 
Biographical notes

Mel George received his Bachelors degree in Technology from the Visvesvaraya National Institute of Technology (VNIT), Nagpur, India in 2007 and subsequently a Masters degree in Technology (M.Tech) from the Indian Institute of Technology (IIT), Bombay, India. Presently, he is Senior Research Scientist at Bharat Petroleum Corporation Ltd. His varied research interests include renewable energy modeling, solar PV fabrication and characterization, robotics, power systems, distribution automation and smart grids. He is a member of the IEEE, the IEEE PES and the IEEE Robotics \& Automation Society. He is also an Affiliate Member of the American Chemical Society (ACS). He has published over 16 papers in refereed international journals and international/national conferences.

Received November 2010

Accepted March 2011

Final acceptance in revised form May 2011 